\title{
AN INVESTIGATION OF OXY-FUEL CUTTING OF MILD STEEL USING PRINCIPLE COMPONENT ANALYSIS AND TAGUCHI TECHNIQUE
}

\author{
N RAVINDER REDDY ${ }^{1}$, V V SATYANARAYANA ${ }^{2}$, P SAMPAT KUMAR $^{3} \&$ \\ V RAMALINGESHWAR RAO ${ }^{4}$ \\ ${ }^{1,3,4}$ Associate professor, Department of Mechanical Engineering, Vidya Jyothi Institute of Technology, \\ Aziznagar, Hyderabad, India \\ ${ }^{2}$ Professor, Department of Mechanical Engineering, Vidya Jyothi Institute of Technology,
}

Aziznagar, Hyderabad, India

ABSTRACT
Oxy fuel cutting process is most widely used in manufacturing and fabrication industries. The properties of
the cut pieces are to be studied, in order to have high quality characteristics. In this investigation, mild steel is employed
for oxy fuel cutting process and the parameters, viz., oxygen pressure, nozzle to plate distance and cutting speed have
been undertaken. Principal Component Analysis coupled with Taguchi method was employed for analyzing the
responses. Optimal parameters were identified by maximizing the Composite Principle Component, comprising the
multiple responses.
KEYWORDS: Mild Steel, Principal Component Analysis, ANOVA \& Kerf

Received: Jul 10, 2017; Accepted: Aug 05, 2017; Published: Aug 28, 2017; Paper Id: IJMPERDAUG201746

\section{INTRODUCTION}

The oxy fuel cutting process is employed in many fabrication industries, to cut thick plates and also when the cut is to be made along a specified contour. Oxy fuel gas cutting process is a useful alternative, compared to other shearing processes. In this process, initially, the ferrous material which was to be cut was heated by oxy fuel flame, to a temperature range of $800-1000^{\mathrm{c}} \mathrm{o}$; and on obtaining the kindling temperature, oxygen at high pressure was directed at the preheated spot, causing rapid oxidation of the metal and finishes the cutting operation Figure 1.

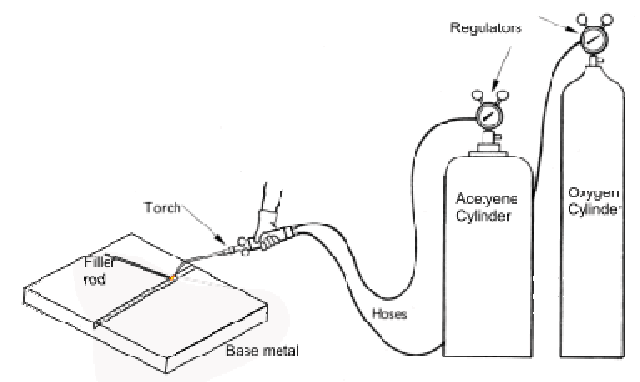

Figure 1: Oxy Fuel Cutting Process

The cutting torch outfit has a central hole for oxygen jet, with surrounding holes for preheating flames. The kerf width of the job widens, when the central hole of the torch increases in its diameter. The cut quality banks upon torch tip diameter, nozzle to plate distance, oxygen flow rate and cutting speed (1). Mild steel and 
stainless steel plates were employed to cut by laser gas cutting operation; it had resulted in improved cut quality and dross free cut at high speeds [2]. The kerf position and groove shape were evaluated by governing the parameters plasma gas flow rate and shielding gas flow rate, in the cutting of mild steel plates by plasma arc cutting process [3]. The economics of the gas cutting process investigation was undertaken for cutting mild steel and cast Iron, of various thicknesses, by varying the parameters and fuel gases [4]. The oxy fuel cutting time of steels would be different and changes with the amount of carbon present in the steel [5]. Also, it is found that, the cutting rate was varied with the oxygen pressure employed during the cutting operation. The formation of iron oxide retarded due to decarburization reactions occurred in the cutting of steels [6].

In many industrial production systems the output responses are governed by many input parameters and warrants a large number of experiments to be conducted to cover entire domain; one economical method of conducting the process is through Taguchi parameter design [7]. However, conventional Taguchi method could effectively establish optimal parameter settings for single response only. Wherever multi responses with conflicting objectives are present Principal Component Analysis (PCA) Taguchi method is adopted [8].

Laser cutting application is studied in metal matrix composites and the analysis is carried out by Taguchi method and PCA [9]. In the stir casting process, the parameters are optimized by PCA Taguchi method [10]. Taguchi method, Response surface methodology and statistical models are used to evaluate the quality characteristics of laser cut components [11].

In this investigation, oxy fuel cutting process is employed for cutting the mild steel plates and the responses are analyzed by PCA Taguchi method.

\section{EXPERIMENTAL METHOD}

Materials Employed

AISI 1010 designated mild steel is employed for oxy fuel cutting process and thickness of the plates used for the cutting process is $7 \mathrm{~mm}$. The properties of the metal employed for cutting operation are given in Table 1.

Table 1: Chemical Composition and Mechanical Properties of Mild Steel AISI 1010

\begin{tabular}{|c|c|c|c|c|}
\hline$\%$ c & $\%$ Man & \% Fe & $\begin{array}{c}\text { Tensile } \\
\text { Strength (Map) }\end{array}$ & Hardness (HRC) \\
\hline 0.1 & 0.45 & balance & 320 & 80 \\
\hline
\end{tabular}

\section{Experimental Parameters}

For cutting operation three parameters namely oxygen pressure, cutting speed and nozzle to plate distance are chosen each at two levels. The Table 2 shows the parameters and the levels at which they are operated during experimentation. Trial runs are conducted to set the levels of the parameters.

Table 2: Experimental Parameters

\begin{tabular}{|c|l|l|c|c|}
\hline S No & \multicolumn{1}{|c|}{ Parameter } & \multicolumn{1}{c|}{ units } & Low (1) & High (2) \\
\hline 1 & Oxygen pressure (A) & $\mathrm{Kpa}$ & 150 & 250 \\
\hline 2 & Nozzle to plate distance(B) & $\mathrm{mm}$ & 3.5 & 7.5 \\
\hline 3 & Speed of cutting (C) & $\mathrm{mm} /$ minute & 550 & 800 \\
\hline
\end{tabular}




\section{Design of Experiments}

The experimentation is performed based on L8 Taguchi orthogonal array. This method allows finding the optimized conditions in economical manner. Table 3 show the orthogonal array undertaken [11], which calls for 8 different experiments under various levels of the parameters chosen.

Table 3: L8 Taguchi OA

\begin{tabular}{|c|c|c|c|}
\hline Run & A & B & C \\
\hline 1 & 1 & 1 & 1 \\
\hline 2 & 1 & 1 & 2 \\
\hline 3 & 1 & 2 & 1 \\
\hline 4 & 1 & 2 & 2 \\
\hline 5 & 2 & 1 & 1 \\
\hline 6 & 2 & 1 & 2 \\
\hline 7 & 2 & 2 & 1 \\
\hline 8 & 2 & 2 & 2 \\
\hline
\end{tabular}

\section{Response Property Evaluation}

The pieces are cut by the oxy fuel cutting process and the property evaluation is conducted for further analysis. Hardness of the material adjacent to the Kerf is measured by employing Krystal Elmec-make hardness testing machine. The Kerf widths at the top and bottom of the plates employed are measured by Mitutoyo vernier calipers. The time of cutting is found by a decimal minute stop watch. Figure 2 shows the location of the property evaluation in the cut pieces.
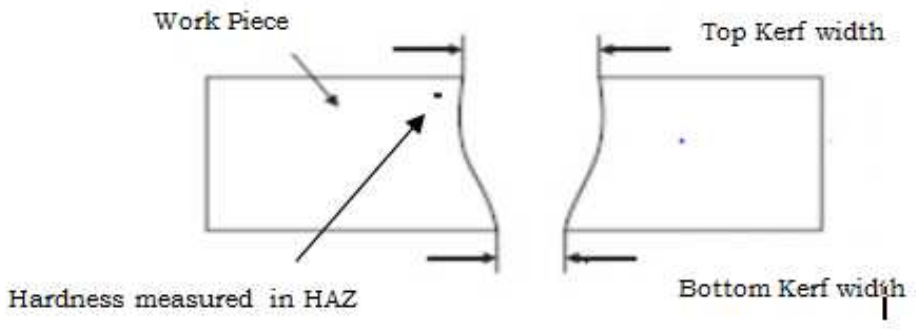

Figure 2: Oxy fuel cut pieces

\section{Principal Component Analysis coupled Taguchi Method}

Optimization of the study undertaken is done with the principle component analysis (PCA), based on Taguchi OA. PCA is a multivariate statistical approach enunciated by Pearson and Hotelling [12]; it converts the multiple correlated responses data into uncorrelated quality values and a mathematical function is formulated to arrive at composite principle component (CPC). The procedural steps of PCA are given below.

Step 1: Array the multiple responses obtained in the study under taken

$\mathrm{X}_{\mathrm{ij}}=\left[\mathrm{x}_{\mathrm{ij}}\right]$ where $\mathrm{x}$ is the response, $\mathrm{i}$ is the number of experimental runs and $\mathrm{j}$ is the number of responses.

Step 2: Normalize the responses employing the lower the better concept

$$
\mathrm{Z}_{\mathrm{i}}(\mathrm{k})=\frac{\max y_{(k)} y_{l}(k)}{\max y_{i}(k)^{-m i n} y_{i}(k)}
$$

Where $Z_{\mathrm{ip}}(\mathrm{k})$ is the normalized value of $\mathrm{k}^{\mathrm{ith}}$ response. 
Step 3: Calculate the Variance - Covariance matrix of the normalized data [13].

Step 4: The Eigen values and Eigen Vectors of the Variance - Covariance matrix obtained in step 3 are computed [13].

Step 5: The principle component of the responses are found by

$\mathrm{x}_{\mathrm{p}}(\mathrm{k})=\sum_{q=1}^{\vec{z}} Z_{i} \sigma_{q}(k) \sigma_{q}(k) \quad$ where $\sigma_{q}(k)$ is the Eigen vector of $\mathrm{k}^{\text {th }}$ response.

Step 6: Total principle component CPC is found by

$$
\mathrm{X}_{\mathrm{i}}=\sum_{k=1}^{i} X_{\mathrm{p}(k)} \mu_{(k)} \quad \text { where } \mu_{(\mathrm{k})}=\frac{\text { eigen value }(k)}{\sum_{i=1}^{k} \text { eigen walue }(k)}
$$

Optimal conditions are arrived at the maximum CPC values. Analysis of variance is conducted to test the hypothesis and there by contribution of each parameter is found.

\section{Results and Analysis}

The measured properties are enlisted in Table 4. Using the lower the better criterion all the responses which are in their respective absolute values are converted into normalized values ranging between zero and unity (Table 5). The normalized responses are subjected to correlation analysis and consequently Variance - Covariance matrix is found (Table 6). The Eigen Values and Eigen Vectors are computed for that Variance - Covariance matrix (Table 7 and 8). Now for each of the normalized response, principle component is computed for all the runs employing the procedure detailed in Step 5 (Table 9). The composite principle component is computed by combining the individual principal components with due weightage from Eigen values (Table 10). The CPC value data have been subjected to ANOVA analysis (Table 11) and the percentage contribution of each of the parameters is also computed.

Table 4: Experimental Results

\begin{tabular}{|c|c|c|c|c|}
\hline Runs & $\begin{array}{c}\text { Hardness } \\
\text { (HRC) }\end{array}$ & $\begin{array}{c}\text { Top-Kerf } \\
\text { Width }(\mathbf{m m})\end{array}$ & $\begin{array}{c}\text { Bottom Kerf } \\
\text { Width(mm) }\end{array}$ & $\begin{array}{c}\text { Time } \\
\text { (Seconds) }\end{array}$ \\
\hline 1 & 85 & 1.84 & 2.3 & 7.5 \\
\hline 2 & 91 & 2.23 & 2.68 & 5.05 \\
\hline 3 & 94 & 2.37 & 2.1 & 7.06 \\
\hline 4 & 88 & 1.92 & 2.63 & 5.91 \\
\hline 5 & 84 & 2.25 & 3.64 & 8.26 \\
\hline 6 & 79 & 2.14 & 2.04 & 5.21 \\
\hline 7 & 83 & 2.48 & 2.65 & 8.94 \\
\hline 8 & 85 & 2.29 & 3.35 & 6.54 \\
\hline
\end{tabular}

Table 5: Normalized Data

\begin{tabular}{|c|c|c|c|c|}
\hline Runs & $\begin{array}{c}\text { Hardness } \\
\text { (HRC) }\end{array}$ & $\begin{array}{c}\text { Top Kerf } \\
\text { Width }(\mathbf{m m})\end{array}$ & $\begin{array}{c}\text { Bottom Kerf } \\
\text { Width }(\mathbf{m m})\end{array}$ & $\begin{array}{c}\text { Time } \\
\text { (Seconds) }\end{array}$ \\
\hline 1 & 0.6 & 1 & 0.8375 & 0.3701 \\
\hline 2 & 0.2 & 0.39 & 0.6 & 1 \\
\hline 3 & 0 & 0.1718 & 0.9625 & 0.4832 \\
\hline 4 & 0.4 & 0.875 & 0.63125 & 0.7789 \\
\hline 5 & 0.666 & 0.3593 & 0 & 0.1748 \\
\hline 6 & 1 & 0.5312 & 1 & 0.9588 \\
\hline 7 & 0.7333 & 0 & 0.61875 & 0 \\
\hline 8 & 0.6 & 0.2968 & 0.18125 & 0.6169 \\
\hline
\end{tabular}


Table 6: Variance and Covariance Matrix

$$
\left[\begin{array}{cccc}
0.0871 & 0.011 & -0.014 & -0.017 \\
0.011 & 0.10 & 0.027 & 0.042 \\
-0.014 & 0.027 & 0.1105 & 0.042 \\
-0.017 & 0.042 & 0.042 & 0.1133
\end{array}\right]
$$

Table 7: Eigen Values

\begin{tabular}{|c|c|c|c|c|}
\hline Responses & Hardness & $\begin{array}{c}\text { Top Kerf } \\
\text { Width }\end{array}$ & $\begin{array}{c}\text { Bottom } \\
\text { Kerf Width }\end{array}$ & Time \\
\hline Eigen value & 0.1850 & 0.1004 & 0.0530 & 0.0726 \\
\hline
\end{tabular}

Table 8: Eigenvectors

\begin{tabular}{|c|c|c|c|}
\hline Hardness & $\begin{array}{c}\text { Top Kerf } \\
\text { Width }\end{array}$ & $\begin{array}{c}\text { Bottom } \\
\text { Kerf Width }\end{array}$ & Time \\
\hline 0.1399 & 0.7848 & -0.4947 & -0.3461 \\
\hline-0.4841 & 0.5703 & 0.6367 & 0.1874 \\
\hline-0.5686 & -0.2379 & 0.0126 & -0.7873 \\
\hline-0.6502 & -0.0476 & -0.5914 & 0.4745 \\
\hline
\end{tabular}

Table 9: PCA Values

\begin{tabular}{|c|c|c|c|c|}
\hline Run & Hardness & Top Kerf Width & Bottom Kerf Width & Time \\
\hline 1 & -1.1170 & 0.8243 & 0.1315 & -0.5040 \\
\hline 2 & -1.1521 & 0.1890 & -0.4344 & 0.0059 \\
\hline 3 & -0.9446 & -0.1540 & -0.1642 & -0.4963 \\
\hline 4 & -1.2329 & 0.6256 & -0.0934 & -0.1018 \\
\hline 5 & -0.1943 & 0.7192 & -0.2040 & -0.0802 \\
\hline 6 & -1.3092 & 0.8042 & -0.7109 & -0.5789 \\
\hline 7 & -0.2492 & 0.4282 & -0.3549 & -0.7409 \\
\hline 8 & -0.5639 & 0.5676 & -0.4703 & -0.0020 \\
\hline
\end{tabular}

Table 10: CPC Values of Responses

\begin{tabular}{|c|c|}
\hline Run & CPC \\
\hline 1 & -0.3734 \\
\hline 2 & -0.5273 \\
\hline 3 & -0.5716 \\
\hline 4 & -0.4321 \\
\hline 5 & 0.0477 \\
\hline 6 & 0.5867 \\
\hline 7 & -0.1842 \\
\hline 8 & -0.1761 \\
\hline
\end{tabular}

Table 11: ANOVA Computation

\begin{tabular}{|l|c|c|c|c|c|}
\hline Source & Dof & SS & MS & F value & \% Contribution \\
\hline A & 1 & 0.5932 & 0.5932 & 10.28 & 58.72 \\
\hline B & 1 & 0.1506 & 0.1506 & 2.61 & 14.90 \\
\hline C & 1 & 0.0355 & 0.0355 & 0.61 & 3.51 \\
\hline Error & 4 & 0.2308 & 0.0577 & & \\
\hline Total & 7 & 1.0101 & & & \\
\hline
\end{tabular}

\section{DISCUSSIONS}

The hardness of the metal in the HAZ adjacent to kerf is more than the parent metal in all the experimental runs. 
At low oxygen pressure, the hardness in HAZ depended on nozzle-to-plate distance and cutting speed. The kerf width is small on the top side while it is broad in the bottom side of the plates in all the runs. With the increase of cutting speed, the time of cutting has reduced.

The variation in kerf widths between top and bottom of the plates is due to the horizontal lag that exists between the entrance and exit points of the cutting Oxygen stream; Also the shape of the cutting flame which is conical with smaller diameter at the tip of the torch and broad at the end gives out the variation in kerf widths. The increase in hardness in the heat affected zone adjacent to kerf is due to aggravated heating. The influence of the parameter, oxygen pressure, is highest with a contribution of $58.12 \%$, while the nozzle to plate distance is governing to an extent of $14.9 \%$ in this process. The cutting speed is the least effecting by $3.51 \%$, only in achieving the responses under consideration. The optimal parameter combination in the achievement of all the responses are at low level for oxygen pressure and cutting speed while nozzle to plate distance is at high level.(Figure 3)

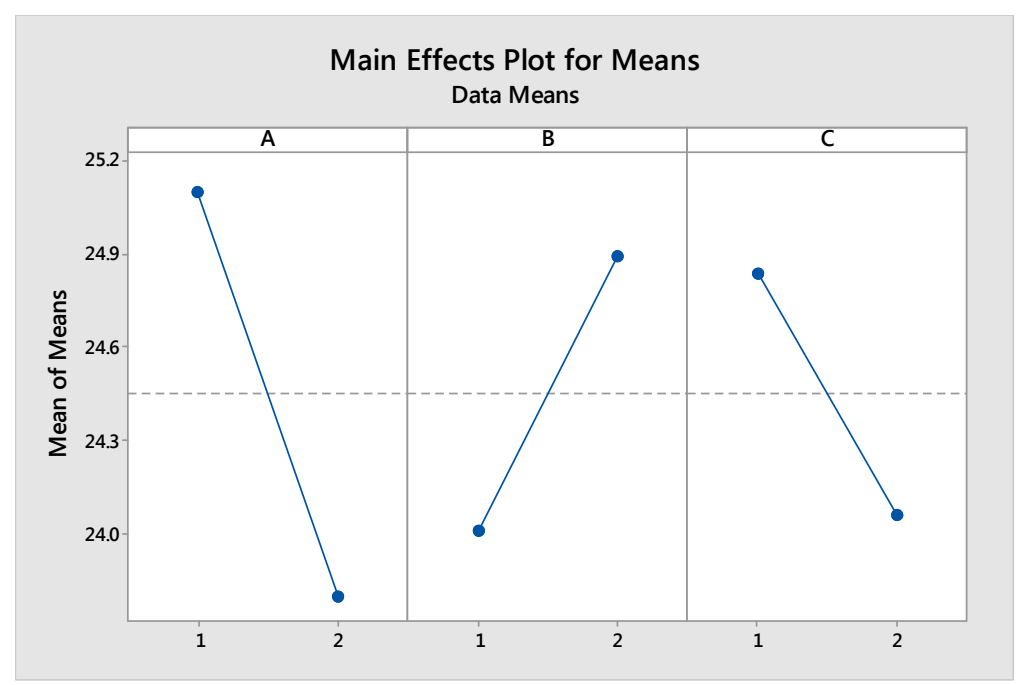

Figure 3: Main Effects of Parameters

\section{CONCLUSIONS}

The horizontal lag and shape of the oxy fuel flame causes the variation in the kerf widths at the top and bottom of the cut plates. The increased hardness in the HAZ is due to heating. Oxygen pressure and nozzle to plate distance have significant influence on the responses. Taguchi coupled principal component analysis is best suitable where multi objective optimization is to be conducted.

\section{ACKNOWLEDGEMENT}

The authors express their deep sense of gratitude to Director and correspondent of Vidya Jyothi Institute of Technology, Hyderabad for the support and encouragement given during this investigation. Also the authors profusely thank all the workshop staff who toiled during experimentation.

\section{REFERENCES}

1. American Welding Society (1997), Welding Hand Book, 8th edition New York.

2. Yoshiaki Arata, Hiroshi Marco, Isamu Miyamoto and Sado Takeuchi, (1981) "Quality in Laser gas cutting stainless steel and its emprovement" Transaction of JWRI, WRI, Osakas university, Osaka, Japan, 1-11, Vol 10, No.2. 
3. R Bini, BM Colosimo, AE Kuttu and M Morno,(2008) "Experimental study of the features of the kerf generated by $200 \mathrm{~S}$ high tolerance plasma arc cutting system" Journal of Material processing Technology, 345-355.

4. Sukani Sunny, Savaj Jayesh, (2015) "Optimization of various gases cutting process by changing various parameters", International Research journal of Engineering and Technology Vol 2, Issue 2, 62-73.

5. Masachaesset Insitute of Technology, (2008), http/ocw.mit.edu.NR/donlyres/materials silence and engineering / 3-051 J Spring.

6. A. V. Adedayo, (2010) "Elucidation on reactions thermodynamics and kinetics of OFCA of steels ", Journal of minerals and Materials characterization and Engineering, Vol 9, No 9, 607-619.

7. P J Ross "Taguchi Techniques for Quality Engineering" New York, Mc Graws Hill 1988.

8. J Antony (2000) "Multi response optimization in industrial experiments using Taguchi Quality loss function and principal component analysis", International Journal of Quality and Reliability Engineering, 16, 3-8.

9. M. L Chaitanya, GVN Santosh and S. Srikanth, (2014) "Multi objective optimization of process parameters in laser beam cutting of Al 7075 10\% Si Cp metal matrix composite using Taguchi method and Principle component analysis" International Journal of Emerging Technology and Advanced Engineering, Vol 4, issue 2, 320-326.

10. Amit Sharma, Rm Blokar, Sanjeev Kumar, (2016) "Multi response optimization of Al 2024/Red mud MMC using principle component analysis", International Journal of Advances in Mechanical and Civil Engineering, Vol 3, issue 6, 23-26.

11. J D Pawar, K H Inamdar, (2015) "Optimization of quality characteristics of Laser Cutting", Journal of Emerging Technologies and Innovative Research, Vol 2, issue 6, pp 1959-1963.

12. Hotelling H, (1993) "Analysis of a complex statistical variables into principle components", Journal of Edue psychol, 24, 417441.

13. Erwin Kreyszing, "Advanced Engineering Mathematics" Willey, loed, Newyork. 
